\title{
Identifikasi Waste Proyek Konstruksi Jalan dengan Menggunakan Metode Lean Project Management
}

\author{
${ }^{1}$ Hatpito, ${ }^{2}$ Anwardi, ${ }^{3}$ Muhammad Ihsan Hamdy \\ ${ }^{1}$ Jurusan Teknik Industri, Fakultas Sains dan Teknologi, UIN Sultan Syarif Kasim Riau \\ J1. HR. Soebrantas KM.15 No.155 Simpang Baru, Panam, Pekanbaru, 28293 \\ Email : harpito@uin-suska.ac.id, anwardi@uin-suska.ac.id,m.ihsanhamdy@uin-suska.ac.id
}

\begin{abstract}
ABSTRAK
Keterlambatan suatu proyek konstrukdi dapat terjadi akibat tidak produktifnya setiap elemen-elemen yang terlibat didalam proyek tersebut. Keterlambatan dapat perdampak pada terjadinya pemborosan (waste). Waste mengakibatkan terjadinya kerugian biaya pada suatu proyek konstruksi. Perbaikan dengan metode Lean Project Management dilakukan dalam penelitian ini. Waste yang terjadi di identifikasi dengan metode WAM (Waste Assessment Model). Berdasarkan hasil identifikasi didapatkan waste yang muncul yaitu waste defect sebesar 20,68\%, waste inventory sebesar $18,48 \%$, waste motion $14,56 \%$, waste overproduction sebesar 13,37, waste waiting 12,83\%, waste transportation 10,48\% dan design and service 2,93\%. Kerugian biaya akibat waste tersebut adalah sebesar Rp. 87.362.572. Faktor yang menyebabkan terjadinya waste tersebut adalah lingkungan yaitu cuaca yang tidak dapat diprediksi, terjadi kerusakan pada mesin, keterlambatan ketersediaan material, penyimpanan material yang tidak pada tempatnya, serta pekerja yang tidak ahli..
\end{abstract}

Kata Kunci: Lean Project Management, Waste, Waste Assessment Model

\section{Pendahuluan}

Dalam dunia konstruksi, pemborosan merupakan salah satu faktor yang harus dihilangkan. Hal ini dikarenakan, disamping pemborosan tidak menambah nilai dalam sebuah proyek, pemborosan juga merupakan salah satu faktor yang dapat menimbulkan kerugian bagi pihak pelaksana proyek.

Berdasarkan wawancara langsung dengan pihak pelaksana proyek, keterlambatan proyek disebabkan oleh beberapa faktor yaitu lamanya keluar hasil tes material sebelum digunakan, terjadi kerusakan alat yaitu rusaknya motor greder dan eskavator, dan faktor cuaca yang tidak menentu. Selain itu terjadi penambahan volume dari kontrak awal, serta terlambatnya material agregat B untuk sampai ke tempat proyek yang disebabkan oleh kerusakan alat trasportasi. Waste waiting seperti itu dapat mengakibatkan terjadinya keterlambatan pelaksanaan proyek dan pihak kontraktor perlu penambahan waktu penyelesaian proyek serta penambahan biaya yang seperti biaya sewa mobil, konsumsi, biaya alat berat, bensin, upah pekerja harian dan biaya ATK.

Untuk mengatasi permasalahan tersebut maka perlu dilakukan identifikasi terhadap waste yang terjadi dengan pendekatan Lean Project Management agar pengerjaan proyek dapat dilakukan tepat waktu, tepat biaya dan memnuhi kualitas yang di syaratkan. Untuk mengetahui hubungan antar waste, digunakan metode Waste Assessment Model (WAM).

\section{Tinjauan Pustaka}

\section{Pihak Yang Terlibat dalam Proyek Konstruksi}

Husen (2009) dikutip oleh Gunawan (2014) menyatakan bahwa agar keinginan dan kebutuhan masing-masing pihak dalam pelaksanaan suatu proyek dapat direalisasikan dalam suatu usaha bersama dalam untuk pencapaian suatu sasaran dan tujuan, maka perlu dilakukan indetifikasi terhadap organisasi atau individual yang terlibat, baik dari internal maupun eksternal, yang berperan pada proyek, dan harus diantisipasi selama proyek berlangsung.

Saqib dkk (2008) dikutip oleh Gunawan (2014) menyatakan sejumlah faktor-faktor yang mempengaruhi kesuksesan pelaksanaan proyek konstruksi yaitu:

1. Kategori manajemen proyek

2. Kategori faktor yang berkaitan dengan pengadaan

3. Kategori faktor yang berkaitan dengan owner

4. Kategori faktor yang berkaitan dengan konsultan atau tim perencana

5. Kategori faktor yang berkaitan kontraktor

6. Kategori faktor yang berkaitan dengan manajer proyek

7. Kategori faktor yang berkaitan dengan lingkungan kerja dan bisnis.

Setiap proyek mempunyai batasan yang berbeda terhadap ruang lingkup, waktu, biaya, yang biasanya disebut sebagai triple constraint (Tiga Kendala) (Laksamana, 2011). 


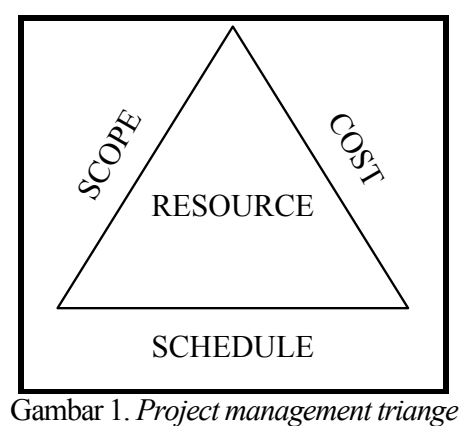

\section{Keterlambatan Proyek Konstruksi}

Pelaksanaan proyek yang tidak sesuai
dengan rencana, dapat mengakibatkan keterlambatan proyek. Kraiem dan Dickman yang dikutip oleh Messah (2013) menyatakan, keterlambatan dapat dibagi menjadi 3 jenis utama, yaitu:

1. Keterlambatan yang tidak dapat dimaafkan (Non Excusable Delays)

2. Keterlambatan yang dapat dimaafkan (Excusable Delays)

3. Keterlambatan yang layak mendapat ganti rugi (Compensable Delays)

Berdasarkan 3 jenis utama keterlambatan, maka penyebab keterlambatan proyek dapat dikelompokan sebagai berikut (Messah, 2013):

1. Non Excusable Delays.

Penyebab- penyebabnya adalah:

a. Identifikasi, durasi, dan rencana urutan kerja yang tidak lengkap dan tidak tersusun dengan baik.

b. Ketidaktepatan perencanaan tenaga kerja

c. Kualitas tenaga kerja yang buruk

d. Keterlambatan penyediaan alat/material akibat kelalaian kontraktor

e. Jenis peralatan yang digunakan tidak sesuai dengan proyek

f. Mobilisasi sumber daya yang lambat

g. Banyak hasil pekerjaan yang harus diulang atau diperbaiki karena cacat atau salah

h. Kesulitan finansial.

i. Kurangnya pengalaman kontraktor

j. Koordinasi dan komunikasi yang buruk dalam organisasi kontraktor

k. Metode kontruksi atau teknik pelaksanaan yang tidak tepat atau salah

1. Kecelakaan kerja yang terjadi pada pekerja

2. Excusable Delays

Penyebab-penyebabnya adalah:

a. Terjadinya hal-hal yang tak terduga seperti banjir badai, gempa bumi, tanah longsor, kebakaran, cuaca buruk.

b. Lingkungan sosial politik yang tidak stabil

c. Respon dari masyarakat sekitar yang tidak mendukung adanya proyek
3. Compensable Delays

Penyebab-penyebabnya adalah:

a. Penetapan pelaksanaan jadwal proyek yang amat ketat

b. Persetujuan ijin kerja yang lama

c. Perubahan lingkup pekerjaan / detail konstruksi

d. Sering terjadi penundaan pekerjaan

e. Keterlambatan penyediaan meterial

f. Dana dari pemilik yang tidak mencukupi

g. Sistem pembayaran pemilik ke kontraktor yang tidak sesuai kontrak.

h. Cara inspeksi atau kontrol pekerjaan birokratis oleh pemilik

\section{Manejemen Proyek}

Manajemen Proyek adalah penerapan ilmu pengetahuan, keahlian dan keterampilan, cara teknis yang terbaik dan dengan sumber daya yang terbatas, untuk mencapai sasaran dan tujuan yang telah ditentukan agar mendapatkan hasil yang optimal dal hal kinerja biaya, mutu dan waktu, serta keselamatan kerja (Husen, 2009).

Menurut Siswanto (2007) dikutip oleh Untu (2014) dalam manajemen proyek, penentuan waktu penyelesaian kegiatan ini merupakan salah satu kegiatan awal yang sangat penting dalam proses perencanaan karena penentuan waktu tersebut akan menjadi dasar bagi perencanaan yang lain, yaitu:

1. Penyusunan jadwal (scheduling), anggaran (budgeting), kebutuhan sumber daya manusia (man power planning), dan sumber organisasi yang lain.

2. Proses pengendalian (controlling).

Manajemen Proyek meliputi tiga fase (Heizer dan Render, 2005 dikutip oleh Untu, 2014), yaitu :

1. Perencanaan.

2. Penjadwalan.

3. Pengendalian.

Beberapa aspek yang dapat diidentifikasi dan menjadi masalah dalam manajemen proyek serta membutuhkan penanganan yang cermat adalah sebagai berikut (Husen, 2009):

1. Aspek Keuangan

2. Aspek Anggaran Biaya

3. Aspek Manajemen Sumber Daya Manusia

4. Aspek Manajemen Produksi

5. Aspek Harga

6. Aspek Efektivitas dan Efisiensi

7. Aspek Pemasaran

8. Aspek Mutu

9. Aspek Waktu 


\section{Lean Construction}

Lean Construction merupakan suatu terjemahan dan adaptasi dari konsep Lean Manufacturing dari Lean Production yang dikembangkan Toyota oleh Ohno serta penelitian secara terus menerus dari suatu proses disain dan pelaksanaan konstruksi. Tidak sama seperti Lean Manufacturing, Lean Construction berfokus terhadap proses produksi suatu proyek (Yudakusumah, 2012).

\section{Lean Project Management}

Lean Management pertama kali dikembangkan di perusahaan Jepang terutama oleh perusahaan otomotif dari jepang yang sangat terkenal di berbagai negara termasuk Indonesia. Lean Management berarti metode sistematis dan integratif yang diimplementasikan secara berkesinambungan untuk meminimalisir dan mencegah adanya pemborosan ataupun prosesproses yang tidak bernilai tambah (non value added) dengan cara perbaikan berkelanjutan (continuous improvement) melalui pemetaan value stream (peta yang memperlihatkan proses nyata secara lebih rinci, mengandung informasi yang lengkap seperti tahapan proses, lead time, antrian, dan lain-lain), yang melibatkan seluruh karyawan baik dari tingkatan top management sampai tingkatan yang terendah (Untu, 2014).

\section{Prinsip-prinsip Lean Project Management}

Adapun prinsip-prinsip dalam Lean Project Management adalah sebagai berikut (Untu, 2014):

1. Project System

a. Identifikasi waste

b. Identifikasi detail pekerjaan dengan Work Breakdown Structure (WBS),

2. Leading People

a. Identifikasi Stakeholder yang berkaitan.

b. Mengelola Stakeholder, dengan pendefinisian roles tiap-tiap stakeholder, dengan menggunakan matriks RICA, digunakan untuk proyek yang berhubungan dengan banyak pihak (biasanya hingga ratusan)

3. Chartering

Chartering merupakan suatu tahap pendefinisian visi dan tujuan proyek, dan menempatkan otoritas kepada pemimpin proyek untuk rencana proyek.

4. Right solution

Pengambilan solusi ini digunakan dalam pemilihan solusi untuk menangani waste yang berpotensi muncul saat pelaksanaan proyek
5. Managing Variation

Variasi di dalam proyek diartikan ketidakpastian, untuk itu pihak pelaksana perlu memanage variasi, dengan cara mengestimasi sebelum pelaksanaan proyek baik dari segi biaya, waktu (penjadwalan) dan sumber daya yang digunakan.

6. Project Risk Management

7. Project Plan

8. Eksekusi

a. Proses pengendalian proyek

b. Memonitor kinerja waktu

c. Mengembangkan sistem biaya atau jadwal terintegrasi

\section{Waste (Pemborosan)}

Taiichi Ohno, seorang eksekutif Toyota, merupakan orang pertama yang mencetuskan tujuh macam pemborosan. Kemudian Linker menambahkan satu jenis pemborosan pada tujuh macam pemborosan tersebut (Daonil, 2012).

Waste yang terjadi pada proses produksi berbeda dengan waste pada proyek konstruksi. Yang membedakan antara seven waste dengan eight waste Womack adalah penambahan waste baru yaitu design of goods and services that do not satisfy customer needs.. Berikut ini adalah penjabaran dari eight waste (Baskara, 2012) :

1. Defects in production

2. Overproduction of items no one wants

3. Inventory waiting to be processed.

4. Unneeded processing

5. Unnecessary transport of goods

6. Unnecessary movement of people

7. People waiting for input to work on

8. Design of goods and services that do not satisfy customer needs

\section{Waste Assessment Model (WAM)}

Waste Assessment Model merupakan suatu model yang dikembangkan untuk menyederhanakan pencarian dari permasalahan waste dan mengidentifikasi untuk mengeliminasi waste (Rawabdeh, 2005 dikutip oleh Khannan, 2015). Model ini menggambarkan hubungan antar seven waste (O: Overproduction, P: Processing, I: Inventory, T: Transportation, D: Defects, W: Waiting, dan M: Motion). 


\section{Metode Penelitian}

Metode penelitian menguraikan mengenai tahapan-tahapan dari penelitian yang dilakukan.

\begin{tabular}{|l|}
\hline \multicolumn{2}{|c|}{ Mulai } \\
Studi Pendahuluan \\
Melakukan observasi dan survey lapangan proyek \\
jalan di desa pangkalan makmur, kecamatan dayun, \\
kabupaten siak
\end{tabular}

Gambar 2. Flowchart penelitian

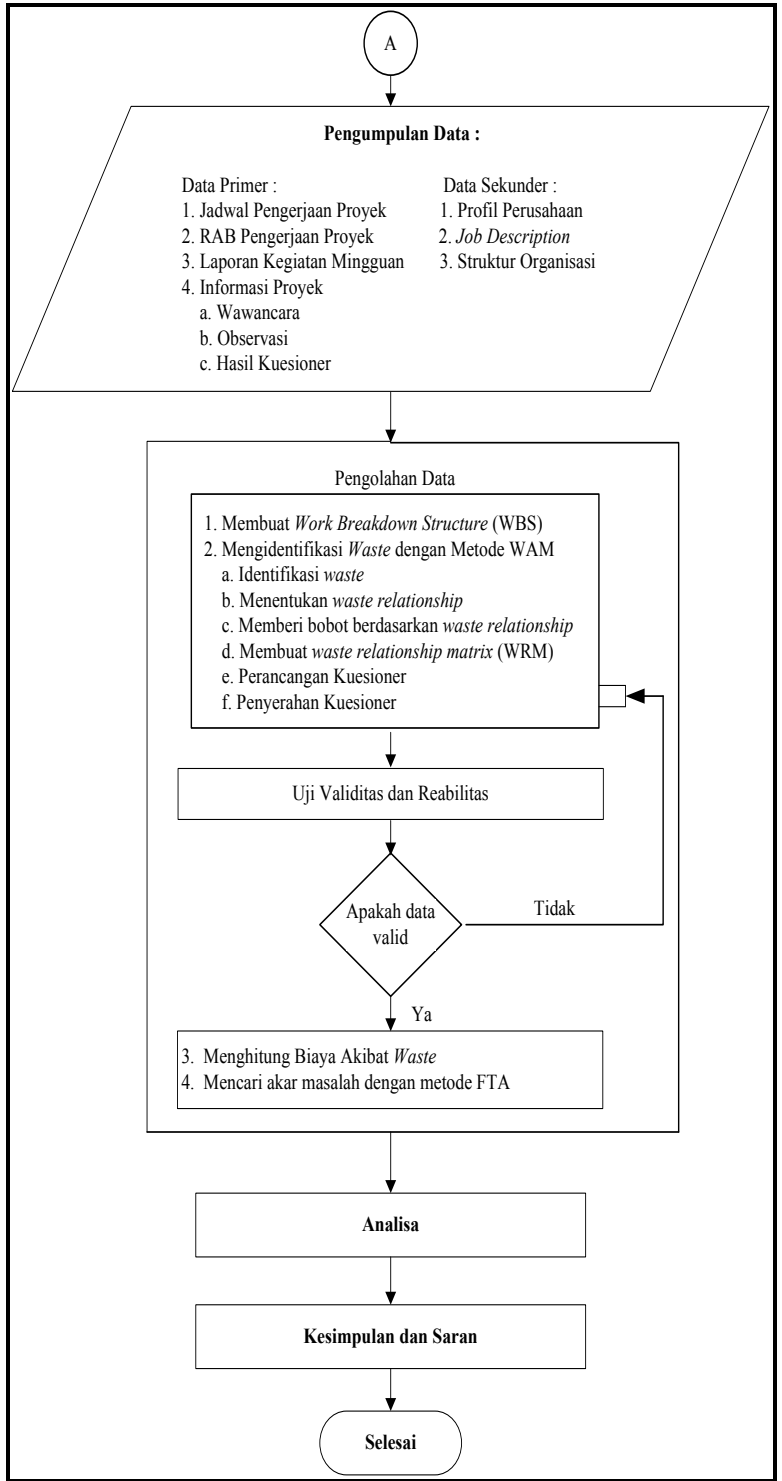

Gambar 3. Flowchart penelitian (lanjutan)

Metode yang digunakan dalam penelitan ini adalah Metode Lean Project Management yang berbasis pada Waste Assessment Model (WAM). Analisis penyebab waste menggunkan metoda Fault Tree Analysis.

\section{Hasil dan Pembahasan}

Indentifikasi waste dilakukan dengan metode waste assessment model (WAM). Data diperoleh dengan cara wawancara dan penyebaran kuesioner. Kuesioner tersebut dibagikan kepada 5 orang.

\section{Seven Waste Relationship}

Seven waste relationship dilakukan untuk megetahui hubungan yang terjadi antara tiap-tiap jenis waste. Pada bidang konstruksi waste yang terjadi terdiri dari 8 jenis, selanjutnya di identifikasi 
hubungan antara tiap waste dengan menyebar kuesioner yang terdiri dari 6 jenis pertanyaan untuk tiap jenis hubungan waste nya.

Berdasarkan hasil perhitungan didapatkan skor keterkaitan antar waste yang kemudian dikonversikan kedalam symbol.

Tabel 1. Konversi rentang skor keterkaitan antar waste

\begin{tabular}{ccc}
\hline Range & Type of relationship & Symbol \\
\hline 17 to 20 & Absolutely necessary & $\mathrm{A}$ \\
13 to 16 & Especially important & $\mathrm{E}$ \\
9 to 12 & Important & $\mathrm{I}$ \\
5 to 8 & Ordinary closeness & $\mathrm{O}$ \\
1 to 4 & unimportant & $\mathrm{U}$ \\
\hline
\end{tabular}

\section{Waste Relationship Matrix (WRM)}

Berdasarkan perhitungan hasil keterkaitan waste, maka dapat dibuat waste relationship matrix.

Tabel 2. Waste matrix value

\begin{tabular}{|c|c|c|c|c|c|c|c|c|}
\hline $\mathrm{F} / \mathrm{T}$ & $\mathrm{O}$ & $\mathrm{I}$ & $\mathrm{D}$ & $\mathrm{M}$ & $\mathrm{T}$ & $\mathrm{P}$ & $\mathrm{W}$ & $\mathrm{DS}$ \\
\hline $\mathrm{O}$ & 10 & 4 & 4 & 6 & 6 & 0 & 4 & 0 \\
\hline $\mathrm{I}$ & 6 & 10 & 6 & 6 & 6 & 0 & 0 & 0 \\
\hline $\mathrm{D}$ & 4 & 6 & 10 & 6 & 6 & 0 & 6 & 0 \\
\hline $\mathrm{M}$ & 0 & 6 & 6 & 10 & 0 & 6 & 6 & 0 \\
\hline $\mathrm{T}$ & 6 & 4 & 4 & 4 & 10 & 0 & 6 & 0 \\
\hline $\mathrm{P}$ & 4 & 6 & 6 & 6 & 0 & 10 & 6 & 0 \\
\hline $\mathrm{W}$ & 4 & 6 & 6 & 0 & 0 & 0 & 10 & 0 \\
\hline $\mathrm{DS}$ & 0 & 6 & 6 & 0 & 0 & 0 & 6 & 10 \\
\hline
\end{tabular}

Untuk penyederhanaan matrix kemudian dikonversikan ke dalam bentuk persentase. Waste relationship matrix dikonversikan ke dalam angka dengan acuan $A=10, E=8, I=6, O=4, U=2$, dan $X=0$. Kemudian dicari skor dan persentasi pada kolom dan baris dari tiap jenis waste seperti di sajikan dalam table 2

\section{Waste Assessment Questionnare (WAQ)}

Nilai waste yang diperoleh dari WRM digunakan untuk penilaian awal pada WAQ berdasarkan jenis pertanyaan. WAQ ini terdiri dari 73 pertanyaan yang berbeda yang masing-masing memiliki pengelompokan tersendiri dan dijawab dengan bobot angka 0; 0,5; dan 1 .

Jumlah pertanyaan kuesioner dikelompokkan dan dihitung berdasarkan jenis pertanyaan from dan to dari tiap jenis waste seperti di sajikan dalam tabel 3 .

Tabel 3. Pengelompokan jenis pertanyaan

\begin{tabular}{|c|c|c|}
\hline No & Jenis Pertanyaan (i) & Total (Ni) \\
\hline 1 & From Overproduction & 3 \\
\hline 2 & From Inventory & 6 \\
\hline 3 & From Defects & 8 \\
\hline 4 & From Motion & 11 \\
\hline 5 & From Transportation & 4 \\
\hline 6 & From Process & 7 \\
\hline 7 & From Waiting & 8 \\
\hline 8 & From Design & 5 \\
\hline 9 & To Defects & 4 \\
\hline 10 & To Motion & 9 \\
\hline 11 & To Transportation & 3 \\
\hline 12 & To Waiting & 5 \\
\hline \multicolumn{3}{|c|}{ Jumlah Pertanyaan } \\
\hline
\end{tabular}

Tabel 4. Hasil perhitungan waste assessment

\begin{tabular}{crrrrrrrr}
\hline & O & I & D & M & T & P & W & DS \\
\hline SKOR (Yj) & 0,66 & 0,65 & 0,64 & 0,64 & 0,63 & 0,62 & 0,64 & 0,59 \\
\hline Pj Faktor & 163,38 & 230,65 & 257,79 & 182,60 & 134,55 & 85,93 & 161,68 & 39,57 \\
\hline Yj Final & 107,58 & 148,72 & 166,35 & 117,14 & 84,35 & 53,62 & 103,23 & 23,54 \\
\hline HA \% & 13,37 & 18,48 & 20,68 & 14,56 & 10,48 & 6,66 & 12,83 & 2,93 \\
\hline Ranking & 4 & 2 & 1 & 3 & 6 & 7 & 5 & 8 \\
\hline
\end{tabular}


Berdasarkan hasil perhitungan pada tabel 3 dapat diliat peringkat waste dalam bentuk grafik adalah:

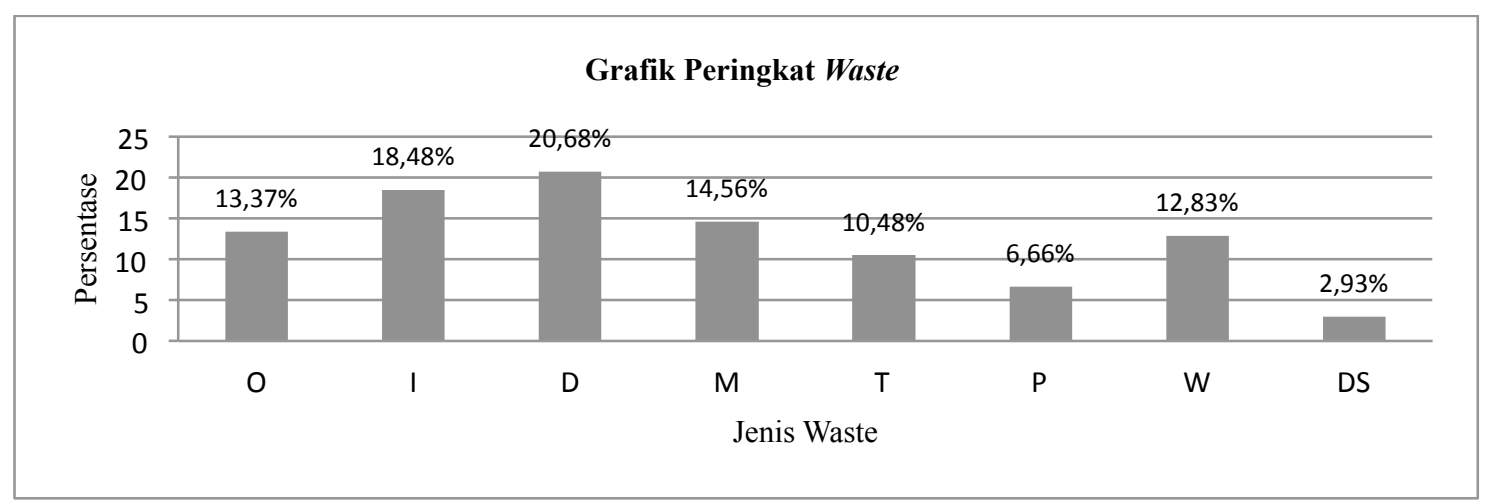

Gambar 4. Peringkat waste

Berdasarkan gambar 4. waste defect merupakan waste yang paling banyak terjadi pada pembangunan jalan yaitu sebesar $20,68 \%$, diikuti oleh waste inventory sebesar $18,48 \%$, waste motion $14,56 \%$, waste overproduction sebesar 13,37 , waste waiting $12,83 \%$, waste transportasi $10,48 \%$ dan desain service 2,93\%. Selanjutnya dicari penyebab dari waste yang timbul yaitu 3 waste tertinggi.

\section{Perhitungan Kerugian}

Adapun kerugian yang muncul akibat waste yang terjadi adalah sebagai beikut:

\begin{tabular}{clr}
\multicolumn{2}{l}{ Tabel 5 . Total kerugian } \\
\hline No & Jenis waste & \multicolumn{1}{l}{ Kerugian } \\
\hline 1 & Inventory & 3.398 .005 \\
\hline 2 & Defect & 5.935 .900 \\
\hline 3 & Waiting & 12.800 .000 \\
\hline 4 & Overproduction & 8.428 .721 \\
\hline 5 & Lainnya & 56.460 .000 \\
\hline Total & & 87.362 .572
\end{tabular}

\section{Analisa Penyebab waste dengan FTA}

\section{Waste Inventory}

Inventory adalah aktifitas yang menempati posisi yang paling penting agar material yang disimpan tetap terjaga. Semua hal harus diperhatikan, jika tidak diperhatikan dengan baik maka akan menimbulkan kerugian dengan adanya penambahan biaya akibat material rusak atau hilang, serta membutuhkan ekstra sumber daya. Berikut adalah FTA dari waste inventory.

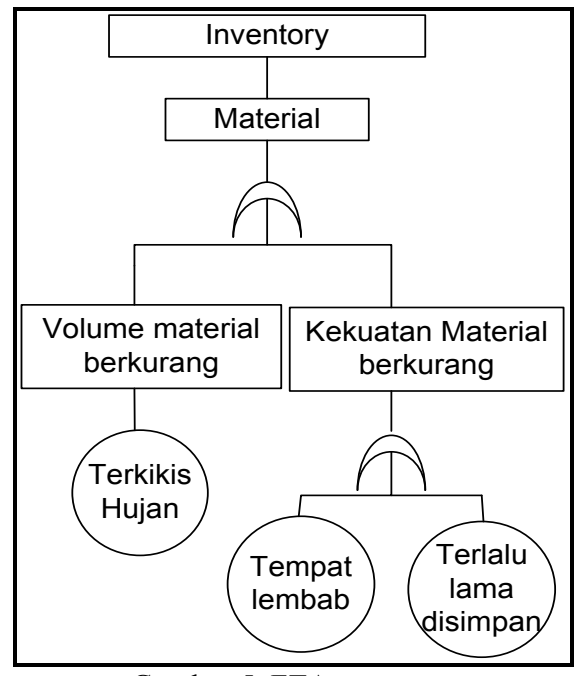

Gambar 5. FTA inventory

\section{Waste Defect}

Defect muncul dikarenakan mesin yang tidak terawat yang akhirnya bekerja secara tidak maksimal dan menghasilkan hasil pekerjaan yang tidak sesuai atau cacat. Selain itu material yang tidak sesuai dan material yang rusak akibat terlalu lama disimpan serta rusak karena tempat penyimpanan yang lembab. Kondisi seperti ini akan menghasilkan produk cacat pula. Perhatikan diagram di bawah ini: 


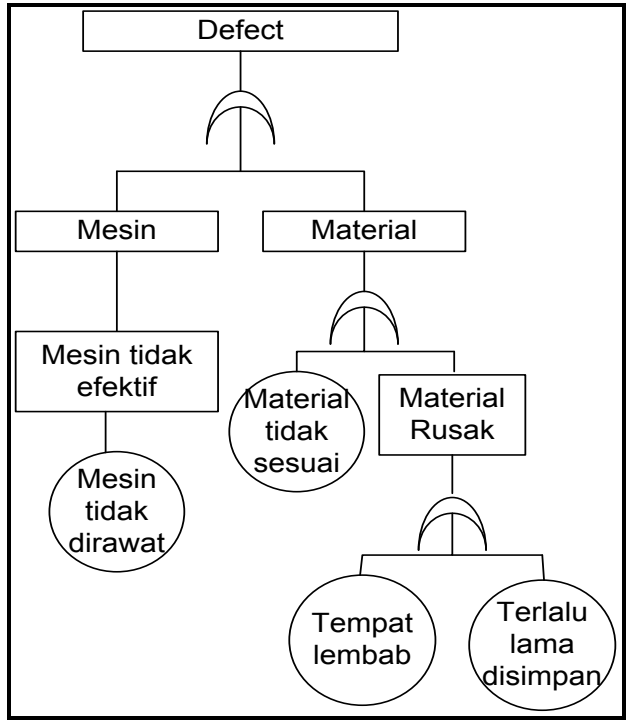

Gambar 6. FTA defect

Waste defect yang muncul dapat mengakibatkan terjadinya penambahan biaya, pengerjaan ulang, pemakaian sumber daya yang tidak semestinya, dan kepercayaan costumer menjadi berkurang. Oleh karena itu waste ini harus bener-bener dihindari karna akan berdampak pada kerugian yang besar.

\section{Waste Waiting}

Waiting meliputi seluruh waktu yang membuat proses pekerjaan terhenti.

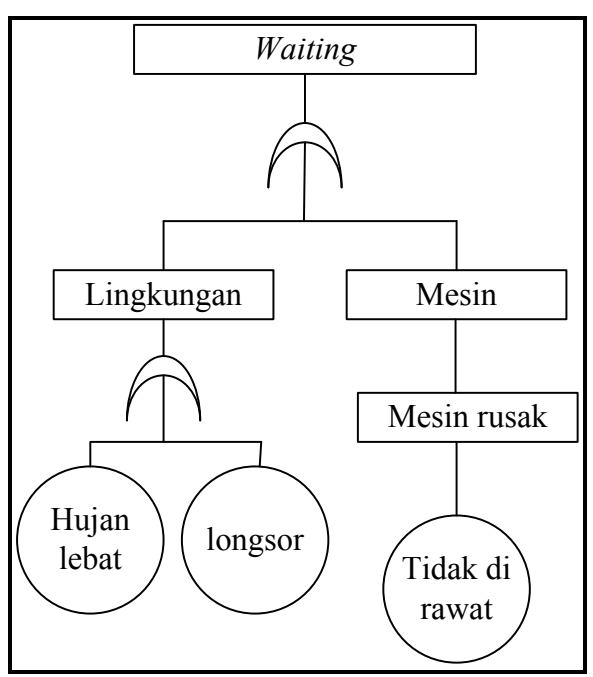

Gambar 7. FTA waiting

Waiting disini yaitu menunggu datangnya material ke lokasi pekerjaan, menunggu mesin selesai diperbaiki, menunggu hujan atau cuaca yang buruk. Berikut merupakan akar permasalahan penyebab waste waiting.

Cuaca merupakan hal yang tidak dapat diatur dan diprediksi oleh manusia, sehingga tidak ada pilihan lain selain menunggu hingga cuaca membaik karena proyek yang dilaksanakan berada di ruang yang terbuka. Hal lain yang terjadi adalah kerusakan dari mesin. Terjadi waktu tunggu untuk menunggu mesin diperbaiki.

\section{Overproduction}

Menyediakan dan memproduksi material dalam jumlah yang berlebih merupakan waste overproduction pada sebuah proyek, dengan begitu terjadi penambahan dana dari yang dibutuhkan. Berikut merupakan akar permasalahan terjadinya waste overproduction.

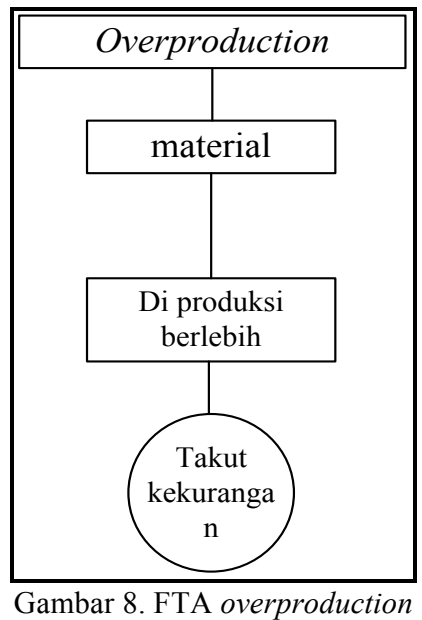

\section{Waste Motion}

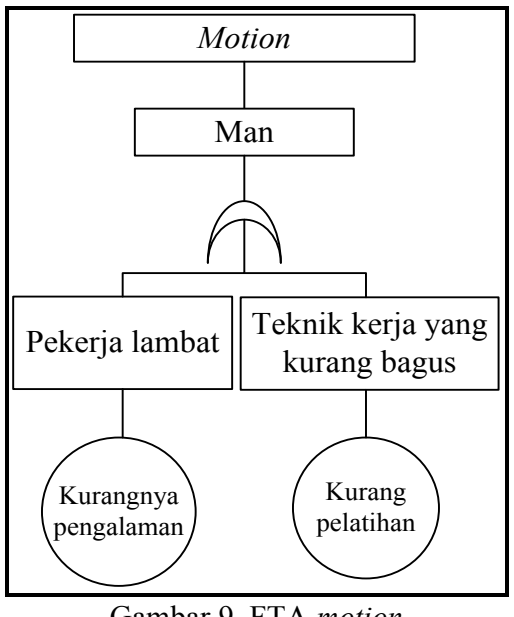

Bentuk waste motion berupa gerakan manusia / individu (operator dan orang-orang yang berhubungan langsung dengan pekerjaan) atau peralatan yang berlebihan, tidak efektif, dan tidak memberikan nilai tambah bagi jalannya proses pengerjaan. Hal ini dapat mengganggu pekerjaan, waktu yang diperlukan menjadi tidak efisien, serta dapat menimbulkan kecelakaan kerja. 


\section{Waste Transportasi}

Lokasi yang dilalui dari penyimpanan pasir dan krikil berada jauh dari lokasi pengerjaan proyek, hal tersebut mengakibatkan terjadinya waste transportasi dimana transportasi yang dugunakan harus bolak balik dari tempt penyimpanan ke tempat proyek berlangsung. Berikut merupakan penyebab munculnya waste transportasi.

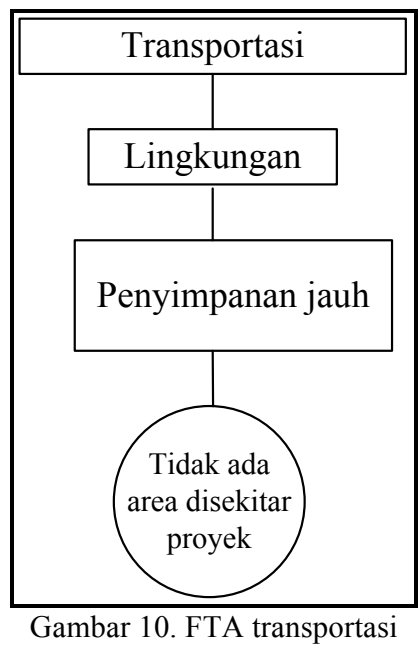

\section{Waste Process}

Waste process muncul akibat tidak terawatnya mesin yang mengakibatnya mesin tidak bekerja secara maksimal yang berdampak pada mudahnya aspal mengalami keretakan atau kerusakan. Jika terjadi hal demikian dimasa pemeliharaan maka kontraktor masih memiliki tanggung jawab untuk memperbaiki

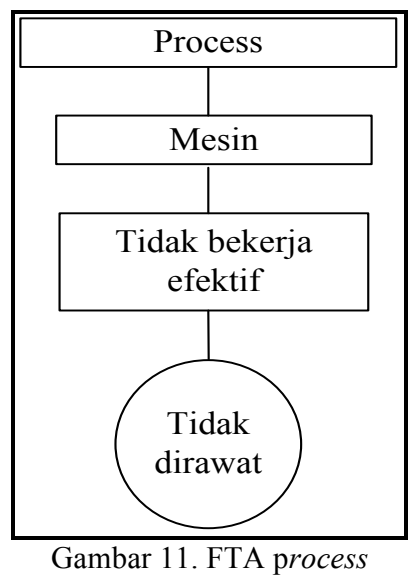

\section{Waste Design and Service}

Design and service adalah waste dimana terjadi pada bagian perubahan design ataupun terjadinya perubahan kontrak (addendum). Hal seperti ini dapat memakan waktu sehingga proyek yang dilakukan dapat tertunda untuk sementara.

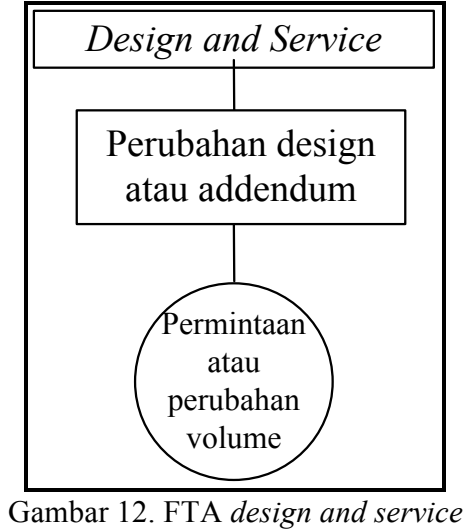

\section{Matriks Evaluasi}

Matriks evaluasi bertujuan untuk mengetahui solusi mana yang layak dipilih berdasarkan beberapa kriteria yang sudah ditentukan sebelumnya dengan melakukan pembobotan. Dari pembobotan tersebut akan didapatkan scooring tiaptiap solusi, sehingga dapat diputuskan solusi mana yang dapat "GO" atau "NOT GO".

Dari model FTA di atas dapat dilihat penyebab-penyebab munculnya waste dari tiap jenis waste berpotensi terjadi pada objek amatan. Dari peristiwa munculnya waste tersebut kemudian diolah ke dalam formulasi if then untuk dapat mengetahui tindakan-tindakan apa yang dapat ditempuh dengan tujuan untuk meminimumkan atau bahkan menghilangkan waste yang dapat diliihat pada tabel 5 .

Matriks evaluasi hanya digunakan pada peristiwa yang memiliki lebih dari satu alternatif solusi dengan waktu implementasi yang bersamaan (pra pelaksanaan, saat pelaksanaan, atau pasca pelaksanaan). Terdapat tiga penyebab yang memenuhi kedua kriteria tersebut yaitu volume material berkurang akibat terkikis hujan, cuaca buruk dan mesin rusak. Ketiga penyebab tersebut di olah kedalam matriks evaluasi sehingga dapat diketahui solusi mana yang lebih optimal untuk diterapkan.

Tabel 6. If then penyebab waste

\begin{tabular}{clc}
\hline \multicolumn{1}{c}{ Controlling Waste } & \multicolumn{1}{c}{ Then } & When \\
\hline $\begin{array}{c}\text { Kualitas } \\
\text { material } \\
\begin{array}{c}\text { kurang bagus } \\
\text { (rusak) }\end{array}\end{array}$ & $\begin{array}{l}\text { Melakukan pembelian } \\
\text { ulang material yang } \\
\text { rusak }\end{array}$ & $\begin{array}{c}\text { Saat } \\
\text { pelaksanaan }\end{array}$ \\
\hline $\begin{array}{c}\text { Volume } \\
\text { matrial } \\
\text { berkurang } \\
\text { akibat terkikis } \\
\text { hujan }\end{array}$ & $\begin{array}{l}\text { Membuat skat } \\
\text { pembatas di tiap sisi }\end{array}$ & $\begin{array}{c}\text { Saat } \\
\text { pelaksanaan }\end{array}$ \\
\cline { 2 - 3 } & hujtuk menghalangi masuk & $\begin{array}{c}\text { Saat } \\
\text { pelaksanaan }\end{array}$ \\
\hline
\end{tabular}




\begin{tabular}{|c|c|c|}
\hline \multirow{2}{*}{ Cuaca buruk } & $\begin{array}{l}\text { Mengajukan surat } \\
\text { pengajuan } \\
\text { keterlambatan } \\
\text { pengerjaan }\end{array}$ & $\begin{array}{c}\text { Saat } \\
\text { pelaksanaan }\end{array}$ \\
\hline & $\begin{array}{l}\text { Melakukan percepatan } \\
\text { pekerjaan saat kondisi } \\
\text { cuaca sudah kembali } \\
\text { normal }\end{array}$ & $\begin{array}{c}\text { Saat } \\
\text { pelaksanaan }\end{array}$ \\
\hline \multirow[t]{2}{*}{ Mesin rusak } & $\begin{array}{l}\text { Melakukan } \\
\text { pengecekan dan } \\
\text { pemeliharaan alat } \\
\text { secara berkala } \\
\end{array}$ & $\begin{array}{c}\text { Saat } \\
\text { pelaksanaan }\end{array}$ \\
\hline & $\begin{array}{l}\text { Menyediakan } \\
\text { peralatan cadangan } \\
\text { pengganti kerusakan }\end{array}$ & $\begin{array}{c}\text { Saat } \\
\text { pelaksanaan }\end{array}$ \\
\hline $\begin{array}{l}\text { Material di } \\
\text { sediakan } \\
\text { berlebih }\end{array}$ & $\begin{array}{l}\text { Mempertimbangkan } \\
\text { hal lain yang mungkin } \\
\text { berguna saat material } \\
\text { tidak diperlukan lagi }\end{array}$ & $\begin{array}{c}\text { Sebelum } \\
\text { pelaksanaan }\end{array}$ \\
\hline $\begin{array}{l}\text { Kurangnya } \\
\text { pengalaman } \\
\text { pekerja }\end{array}$ & $\begin{array}{l}\text { Memilih pekerja yang } \\
\text { memiliki pengalaman } \\
\text { yang banyak dibidang } \\
\text { yang dibutuhkan }\end{array}$ & $\begin{array}{c}\text { Sebelum } \\
\text { pelaksanaan }\end{array}$ \\
\hline
\end{tabular}

\begin{tabular}{|c|c|c|}
\hline $\begin{array}{l}\text { Teknik kerja } \\
\text { yang kurang } \\
\text { bagus }\end{array}$ & $\begin{array}{l}\text { Melakukan pelatihan } \\
\text { terhadap pekerja } \\
\text { lapangan }\end{array}$ & $\begin{array}{c}\text { Sebelum } \\
\text { pelaksanaan }\end{array}$ \\
\hline $\begin{array}{c}\text { Tempat } \\
\text { penyimpanan } \\
\text { material yang } \\
\text { jauh }\end{array}$ & $\begin{array}{l}\text { Menyewa perkarangan } \\
\text { warga sekitar area } \\
\text { proyek }\end{array}$ & $\begin{array}{c}\text { Saat } \\
\text { pelaksanaan }\end{array}$ \\
\hline $\begin{array}{c}\text { Terjadi } \\
\text { perubahan } \\
\text { desain }\end{array}$ & $\begin{array}{l}\text { Seluruh pekerja siap } \\
\text { bekerja ekstra untuk } \\
\text { mempercepat } \\
\text { pekerjaan saat desain } \\
\text { selesai diubah }\end{array}$ & $\begin{array}{c}\text { Saat } \\
\text { pelaksanaan }\end{array}$ \\
\hline
\end{tabular}

Tabel 7. Matriks evaluasi volume matrial berkurang

\begin{tabular}{|c|c|c|c|c|c|}
\hline \multirow{3}{*}{ Kriteria } & \multirow{3}{*}{ Weight factor } & \multicolumn{4}{|c|}{ Volume matrial berkurang akibat terkikis hujan } \\
\hline & & \multicolumn{2}{|c|}{$\begin{array}{l}\text { Memasang terpal untuk } \\
\text { menghalangi hujan masuk }\end{array}$} & \multicolumn{2}{|c|}{$\begin{array}{l}\text { Membuat skat pembatas di tiap } \\
\text { sisi }\end{array}$} \\
\hline & & Ranking & Weight score & Ranking & Weight score \\
\hline (1) & (2) & (3) & $(4)=(2 \times 3)$ & (5) & $(6)=(2 \times 5)$ \\
\hline Biaya & 3 & 4 & 12 & 3 & 9 \\
\hline Waktu & 3 & 4 & 12 & 2 & 6 \\
\hline Dampak Terhadap Hasil & 3 & 3 & 9 & 2 & 6 \\
\hline Resiko & 3 & 3 & 9 & 2 & 6 \\
\hline \multicolumn{2}{|l|}{ Total } & & 42 & & 27 \\
\hline \multicolumn{2}{|c|}{ GO/NOT GO } & \multicolumn{2}{|c|}{$\overline{G O}$} & \multicolumn{2}{|c|}{ NOT GO } \\
\hline
\end{tabular}

Tabel 8. Matriks evaluasi cuaca buruk

\begin{tabular}{|c|c|c|c|c|c|}
\hline \multirow{3}{*}{ Kriteria } & \multirow{3}{*}{ Weight factor } & \multicolumn{4}{|c|}{ Cuaca Buruk } \\
\hline & & \multicolumn{2}{|c|}{$\begin{array}{l}\text { Mengajukan surat } \\
\text { pengajuan keterlambatan } \\
\text { pengerjaan }\end{array}$} & \multicolumn{2}{|c|}{$\begin{array}{l}\text { Melakukan percepatan pekerjaan saat } \\
\text { kondisi cuaca sudah kembali normal }\end{array}$} \\
\hline & & Ranking & $\begin{array}{l}\text { Weight } \\
\text { score }\end{array}$ & Ranking & Weight score \\
\hline (1) & (2) & (3) & $(4)=(2 \times 3)$ & (5) & $(6)=(2 \times 5)$ \\
\hline Biaya & 3 & 5 & 15 & 2 & 6 \\
\hline Waktu & 3 & 3 & 9 & 1 & 3 \\
\hline Dampak Terhadap Hasil & 3 & 4 & 12 & 3 & 9 \\
\hline Resiko & 3 & 3 & 9 & 2 & 6 \\
\hline \multicolumn{2}{|c|}{ Total } & & 45 & & 24 \\
\hline \multicolumn{2}{|c|}{ GO/NOT GO } & \multicolumn{2}{|c|}{$G O$} & \multicolumn{2}{|c|}{ NOT GO } \\
\hline
\end{tabular}


Tabel 9. Matriks evalusi mesin rusak

\begin{tabular}{|c|c|c|c|c|c|}
\hline \multirow{3}{*}{ Kriteria } & \multirow{3}{*}{ Weight factor } & \multicolumn{4}{|c|}{ Mesin rusak } \\
\hline & & \multicolumn{2}{|c|}{$\begin{array}{l}\text { Melakukan pengecekan } \\
\text { dan pemeliharaan alat } \\
\text { secara berkala }\end{array}$} & \multicolumn{2}{|c|}{$\begin{array}{l}\text { Menyediakan peralatan cadangan } \\
\text { pengganti kerusakan }\end{array}$} \\
\hline & & Ranking & $\begin{array}{l}\text { Weight } \\
\text { score }\end{array}$ & Ranking & Weight score \\
\hline$(1)$ & $(2)$ & (3) & $(4)=(2 \times 3)$ & (5) & $(6)=(2 \times 5)$ \\
\hline Biaya & 3 & 2 & 6 & 5 & 15 \\
\hline Waktu & 3 & 5 & 15 & 3 & 3 \\
\hline Dampak Terhadap Hasil & 3 & 4 & 12 & 3 & 9 \\
\hline Resiko & 3 & 3 & 9 & 2 & 6 \\
\hline \multicolumn{2}{|c|}{ Total } & & 42 & & 33 \\
\hline \multicolumn{2}{|c|}{ GO/NOT GO } & \multicolumn{2}{|c|}{$G O$} & \multicolumn{2}{|c|}{ NOT GO } \\
\hline
\end{tabular}

\section{Kesimpulan}

Waste yang teridentifikasi dari yang terbesar hingga yang terkecil adalah waste defect sebesar $20,68 \%$, diikuti oleh waste inventory sebesar $18,48 \%$, waste motion $14,56 \%$, waste overproduction sebesar 13,37, waste waiting $12,83 \%$, waste transportasi $10,48 \%$ dan desain service $2,93 \%$. Waste yang terjadi menyebabkan kerugian sebesar Rp. 87.362.572.

Waste yang terjadi dapat diminimalisir dengan, membuat pelindung penyimpanan material, mengajukan surat pengajuan keterlambatan pengerjaan, melakukan pengecekan alat secara berkala, memilih dan mempekerjakan pekerja yang berpengalaman dibidangnya, melakukan pelatihan terhadap pekerja dan mempersiapkan pekerja untuk bekerja ekstra saat setelah terjadinya perubahan desain.

\section{Daftar Pustaka}

[1] Artika, Dian. Penerapan Metode Lean Project Management dalam Proyek Konstruksi pada Pembangunan Gedung DPRD Kabupaten Ogan Ilir. Jurnal Teknik Sipil dan Lingkungan Vol. 2 No. 1. Palembang, Maret 2014.

[2] Ervianto, Wulfram I. Teori Aplikasi Manajemen Proyek Konstruksi. ANDI. Yogyakarta. 2004.

[3] Gray, Clive. Pengantar Evaluasi Poyek, PT. Gramedia Pustaka Utama, Jakarta. 2007.

[4] Gunawan, Moch. Afifuddin dan Ibnu Abbas Majid. Critical Succes Factors Pelaksanaan Proyek Konstruksi Jalan Dan Jembatan Di Kabupaten Pidie Jaya. Jurnal Teknik Sipil Volume 3 No. 1. Februari 2014.

[5] Husen, Abrar. Manajemen Proyek. Andi Offset. Yogyakarta. 2009.
[6] Messah, Yunita Afliana. Kajian Penyebab Keterlambatan Pelaksanaan Proyek Konstuksi Gedung Di Kota Kupang. Jurnal Teknik Sipil Vol. II No. 2. September 2013.

[7] N. Narsha dan S. Nagabhushan. Enhancing Project Management Efficiency using Lea

[8] $n$ Concepts. IOSR Journal of Mechanical and Civil Engineering (IOSR-JMCE) eISSN: 2278-1684,p-ISSN: 2320-334X, Volume 8, Issue 4. Oktober 2013.

[9] Santoso, Budi. Manajemen Proyek. Graha Ilmu. Surabaya. 2008.

[10] Untu, Silvia Hermina Stevania, Ariestides K. T. Dundu,dan Robert J. M. Mandagi. Penerapan Metode Lean Project Management dalam Perencanaan Proyek Konstruksi (Studi Kasus : Pembangunan Gedung Mantos Tahap III). Jurnal Sipil Statik Vol. 2 No. 6. September, 2014.

[11] Wulandari, Trisya. Analisa Kegagalan Sistem dengan Fault Tree. Skripsi Fakultas Matematika dan Ilmu Pengetahuan Alam Universitas Indonesia Depok. Juli 2011.

[12] Yudakusuma, Teguh. Aplikasi Lean Construction Untuk Meningkatkan Efisiensi Waktu Pada Proses Produksi Di Industri Precast. Tesis Fakultas Teknik Universitas Indonesia Depok. Juli 2012 
Jurnal Hasil Penelitian dan Karya Ilmiah dalam Bidang Teknik Industri 